\title{
WHY DID VESALIUS NOT DISCOVER THE FALLOPIAN TUBES?
}

by

\section{ROBERT HERRLINGER AND EDITH FEINER}

\section{The Pre-Vesalian Knowledge of the Fallopian Tubes}

THE first description of the uterine tubes that has come down to us from early medical literature originates from Herophilus (about 300 B.C.), who referred to

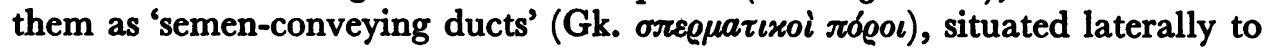
each of the ovaries. According to Herophilus, however, the tubes opened into the bladder, i.e. into the lower end of it. ${ }^{1}$ The term 'semen-conveying duct' or ductus deferens, denoting the organ that is named 'uterine tube' in modern nomenclature, was derived from the concept of analogy between male and female generative organs, which was initiated probably by Herophilus upon his discovery of the ovaries (prior to that of the tubes). The ovaries, consequently, were called the 'female testes'. It was this view which determined Herophilus to locate the termination of his female ductus deferentes in the neck of the bladder!

This doctrine, which exercised a dominating influence upon the anatomical and physiological concepts of the female generative organs until the sixteenth century, led in turn to the classical theory of the mutual existence of semen in both sexes. This 'semen' was supposed to be prepared in the vasa seminaria of the female-just as in the male; however, in contrast to the male semen, it was

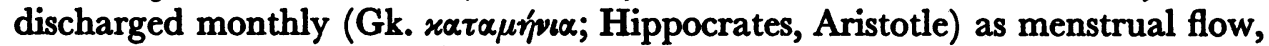
after having undergone incomplete digestion (Gk. $\pi \dot{\varepsilon} \psi \mathbf{L}$, L. coctio).*

The conviction that the tubes terminated in the neck of the bladder was upheld also by Soranus in the second century A.D. ${ }^{2}$

According to Galen (A.D. I30-201), the 'semen-conveying ducts' ended in the horns of the uterus, ${ }^{1}$ an observation which was, in fact, derived from animal anatomy. The uterine tubes of domestic animals (in the case of Galen, ruminants and dogs) do, indeed, lead into uterine angles, since these animals are equipped with a horned uterus (uterus bicornis). ${ }^{3}$

The best anatomical accounts of the tubes originate from Arabic authors, Hali Abas and Avicenna. They observed an enlarged as well as an isthmic part, together with an ampulla of the uterine tube with an oarlike component at the end that was absent in the male."

During the following five centuries the concept of the 'semen-conveying ducts' was based primarily on Galenic texts, and no original contributions were made.

\section{Vesalius' Description of the Tubes}

The ancient doctrine of the analogy between male and female generative

* For further reference see Lesky, E., Die Zeugungs- und Vererbungslehre der Antike und ihre Nachwirkungen, Wiesbaden, Steiner, 1950, p. 132. 


\section{Robert Herrlinger and Edith Feiner}

organs had lost nothing of its attraction even in the sixteenth century. Consequently, Vesalius, too, considered the 'female seminal ducts' or 'semenconveying vessels' the organs analogous to the ductus deferentes of the male. Vesalius expresses his opinion in the following words: 'Since the female seminal vessels correspond to those of the male in shape as well as in function, I shall use the same names for both of them in my lectures.' (Fabrica, v, p. 659, 1555.)

The vasa spermatica, i.e. the vasa ovarica or spermatica of modern nomenclature (PNA), * served as organs for the preparation of semen (its final preparation had been transferred to the 'female testis' since Galen). The distal portion of these vessels, owing to its network of collateral branches, was believed to represent a prerequisite for this function. This was the place where the flow of blood was compelled to cease; what else could be the purpose of this stasis but to bring about its change into the seminal fluid?

The vas semen a teste in uterum deferens originates from the superior pole of the testis:

The vessel which conveys (deferens) the semen (semen) from the testis to the uterus (in uterum)

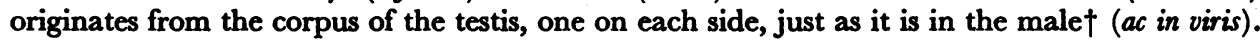
However, it surrounds the testis like a circle instead of being attached to its posterior surface alone. For, starting from the internal basic portion of this corpus varicosum, $\ddagger$ it passes the testis' external side, further, its inferior side, and sometimes also its inner side, its course being coiled, although less than that of a worm-and this is the place where the vessel is attached to the testis (Fabrica, v, p. 659, 1555 ). ${ }^{\mathrm{s}}$

\section{Vesalius' description of the final portion of the vas semen deferens reads as} follows:

In continuation of its course (sporrio) it (the vas semen in uterum deferens) leads slightly upwards, and, after having turned off from the testis, develops several convolutions (revolutiones eas amittit). Finally (ac) it proceeds in serpentines towards the uterus as a round and plane duct, quite similar to a nerve (some of the ancients compared this winding course with small tendrils of vine), and finally it ends in the midst of the uterine horn (in mediam sui lateris cornu sedem), each vessel on its proper side (Fabrica, v, p. 659, 1555).

According to Vesalius' detailed description, the female 'semen-conveying duct' is a vessel displaying a winding course and encircling the ovary. The influence of the concept of analogy is self-evident: course and location of the female seminal duct are reminiscent of epididymis and ductus deferens of the male; the only difference being the fact that the female seminal duct is attached to the testis' circumference instead of to its posterior portion only (as in the case of the male testis).

* Paris Nomina Anatomica.

† Vesalius' description of the ductus deferentes of the male sex, which are to correspond to those of the female, is given below:

'The applantatio of the vas semen deferens to the testis, by the way, is effected by an intima tunica testis which contains a number of pores, because the vas semen deferens has to be hard, strong, and dense to be able to stand injuries. The substance of the testis, however, has to be slack and soft (opportuerit). Nature in her prudence (prudens natura) has arranged this, here as anywhere else: objects opposite in substance are not to be composed directly but only by means of a link (Misi copula aliqua smicitiae societatisque consiliatrice in medium conjecta). . . At that place where the vasa seminaria are entering the testis, this intima tunica testis is thin, in fact, softer than at any other part of the (testis') corpus. ... (Fabrica, v, p. 646, 1555.)

In the Vesalian nomenclature the corpus varicosum is the organ analogous to the plexus pampiniformis of modern nomenclature (PNA). 


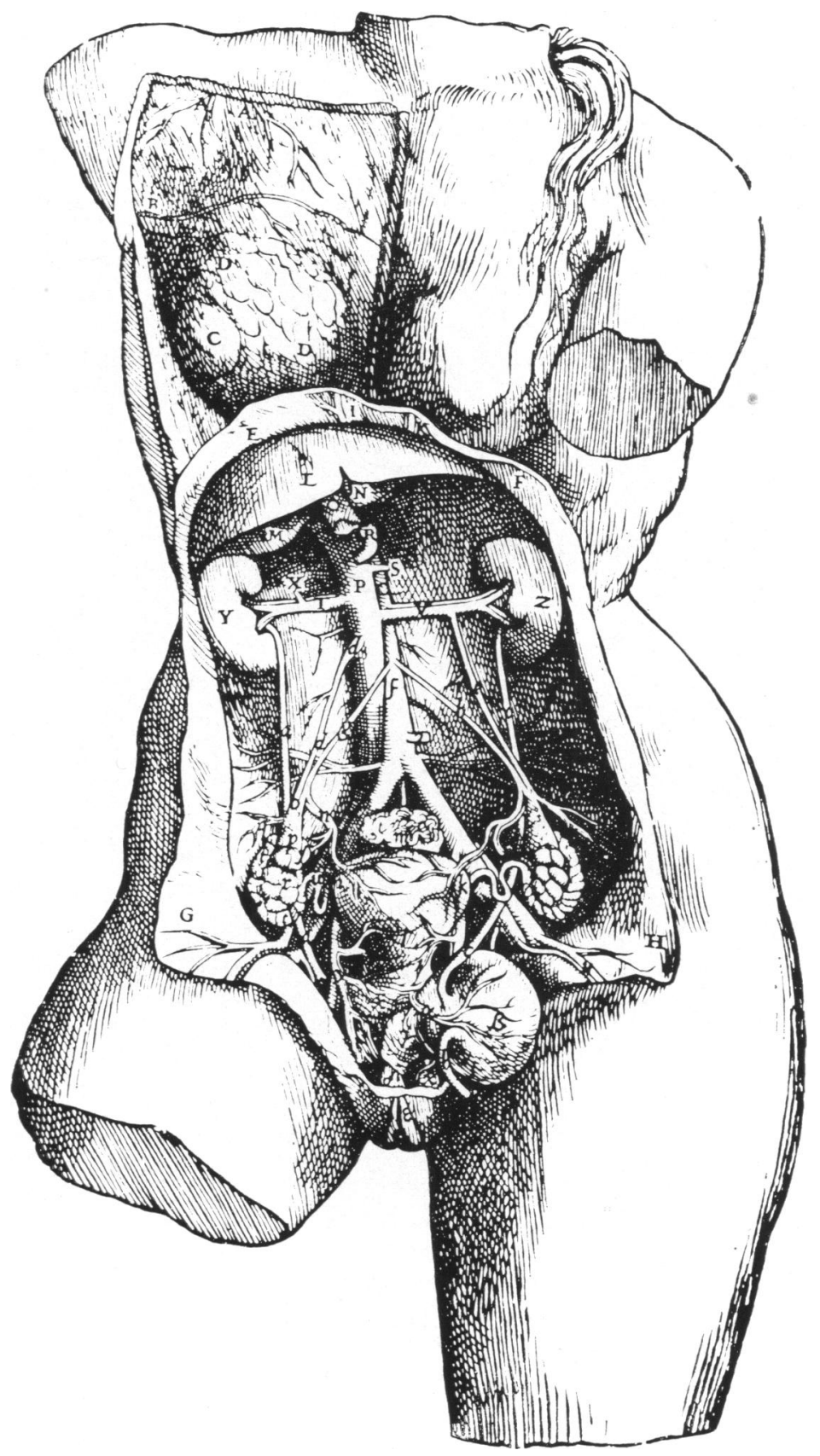

Fig. I 


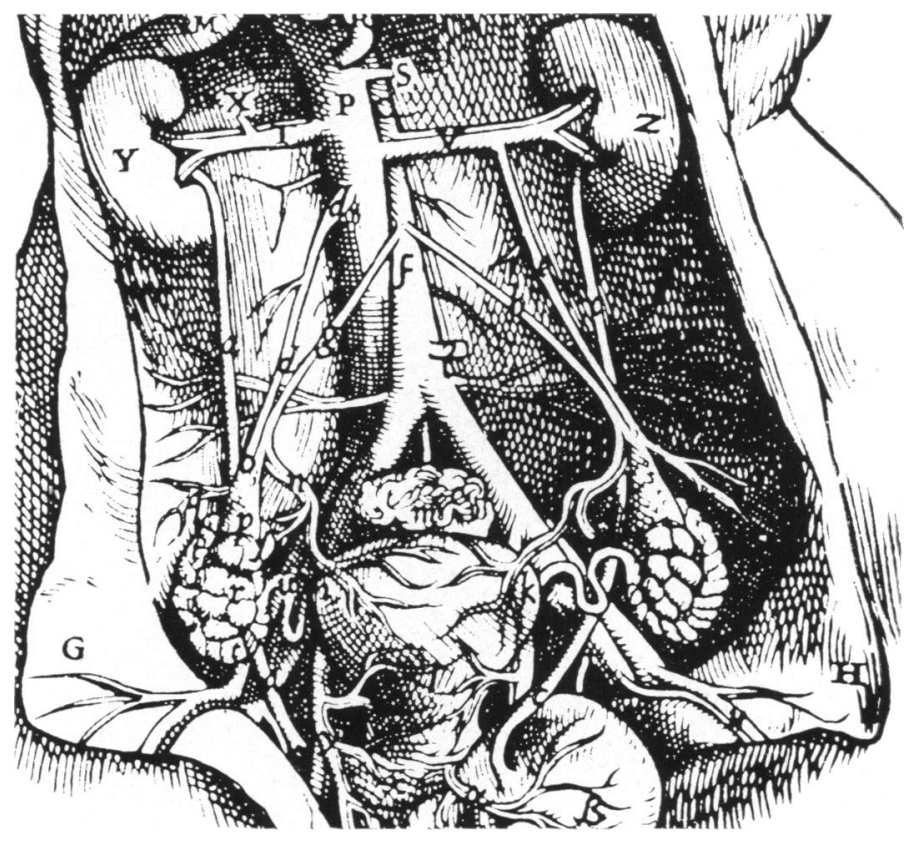

Fig. 2

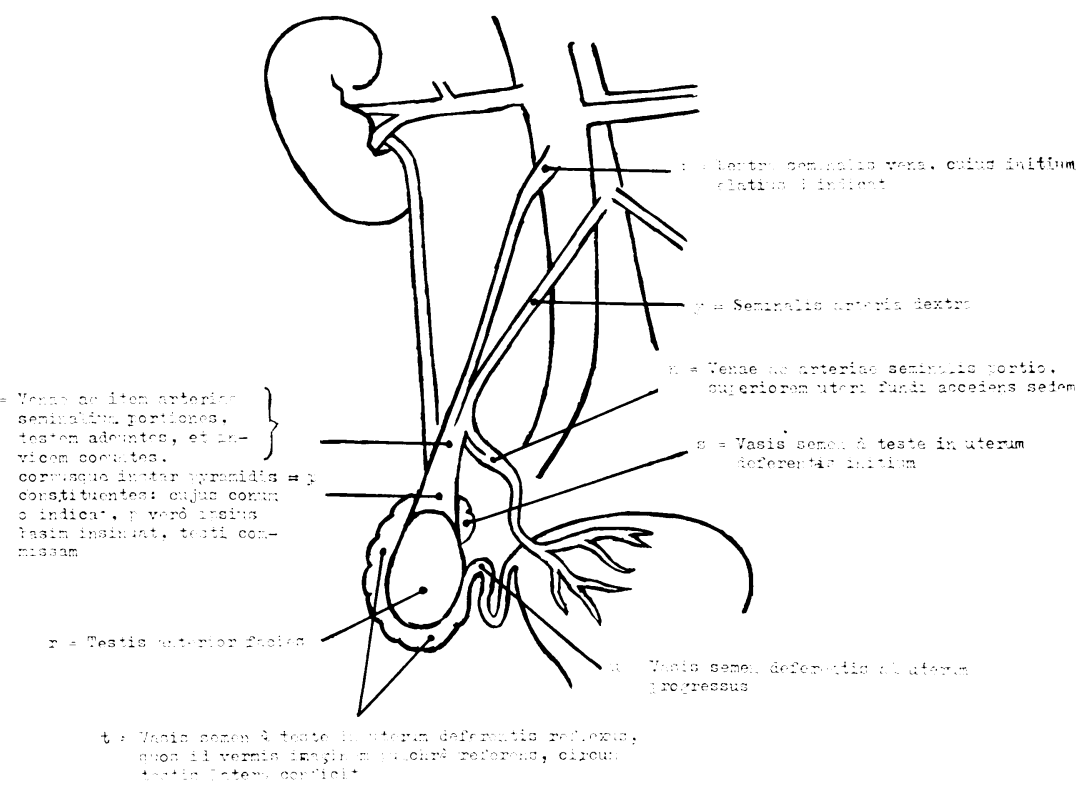

Fig. 3 


\section{Our Explanation}

The organ which Vesalius is describing so minutely can be nothing else but what has been named tuba uterina since Fallopius' discovery (see p. 339). Vesalius presents a very fine description of the morphological difference in the connection between testis and epididymis on the one hand, and ovary and uterine tube on the other: the fairly tight nature of the first, particularly at the posterior of the testis, and the loose one of the second, extending almost completely to the testis' circumference. What Vesalius failed to recognize is but one fact, namely, that this ductus semen deferens does not originate from the organ which it embraces 'like a worm'; or, in other words, that near the origin (Vesalius speaks of progressus) the 'duct' is just covering the 'testis' without being connected with it.

We are aware of the fact that our opinion is not in line with that of O'Malley' and also with many other authors of the elder generation. In order to explain our views we should like to draw attention to one of Vesalius' pictures, namely, fig. 25 of Liber V (fig. I), which corresponds with the text in minute detail, as may be seen in the enlarged print (fig. 2).* The testis, demonstrated correctly, i.e. in a vertical position, is surrounded by a vermiform organ, originating from the top and extending over the medial side of the testis. This, too, is correct. The 'worm' is coiling towards the uterine fundus and leading into the so-called 'tubal angles'. Two vessels are descending from above, one artery and one vein, which join to a body of conic and pyramidal shape. The basic portion of this 'corpus' merges into the testis. Prior to their communication, referred to as anastomosis in the text, both vessels are sending out one branch each (n), which leads to the upper portion of the uterine fundus. The legend to fig. 25 gives the exact description of the above. $\dagger$

\section{The Role of Animal Anatomy}

According to Vesalius, and prior to him also to Galen, the uterine tubes are leading into the cornua uteri, a description which is quite correct. In the Vesalian nomenclature the term cornu is used in the sense of 'angle', denoting the widening of the cavity (Fabrica, v, p. 653, 1555) as well as of the myometrium of the uterine fundus (Fabrica, v, p. 652,1555 ). Thus it is not quite clear whether (in the above cited description) Vesalius is referring to the external or internal opening of the tube into the uterus, i.e. according to modern nomenclature (PNA), to the pars isthmica outside, or to the pars interstitialis within the uterus.

Vesalius' cornua in the meaning of angles

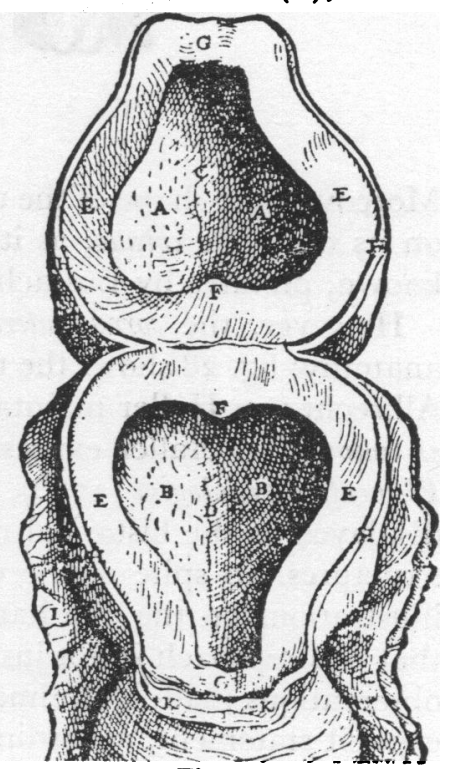

Fig. 4.

- The symbols and legend used in the explanatory figure (fig. 3) are the same as given by Vesalius (p. $5^{82}$ of the 1555 edition).

it appears to be somewhat surprising that Saunders and O'Malley ( $p .172)$ refer to spermatic vessels $\left(\mathcal{N}^{\prime}\right.$ '), confused with the uterine or Fallopian tube. Likewise, they refer to ' $t$ ' as representing the epididymis, although this term does not occur in the legend to Vesalius' picture (6). 


\section{Robert Herrlinger and Edith Feiner}

correspond-in modern nomenclature - to a recess on both sides of the myometrium within the uterine fundus, which causes the pear-shaped configuration of the uterus.

It is somewhat surprising that Vesalius' natural-sized figure of the extirpated uterus (fig. 27 of Liber V) (fig. 4) does not show either the tubes or their mouth.

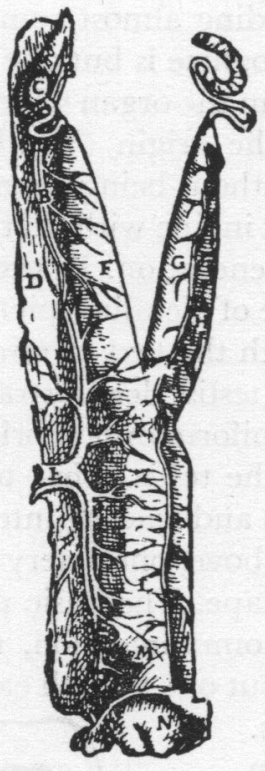

Fig. 5.

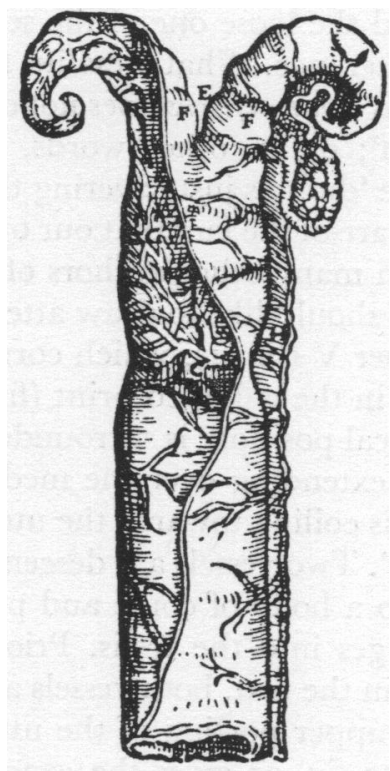

Fig. 6.

Moreover, the shape of the uterine cavity does not even indicate any elongation on its sides like cormua, as it can be observed, for example, on some, less wellknown, pictures by Eustachius (Tab. XIIII).

However, the cornua uteri are demonstrated on two pictures from animal anatomy: fig. 28 shows the uterus of a dog (fig. 5), fig. 29 that of a cow (fig. 6). Albrecht von Haller maintained Vesalius had described only animal uteri, i.e. ex animalibus. Haller expressed his opinion in a footnote* in Book VII of his Elementa Physiologiae (1778), a source still unexcelled for its scientific background displayed in the historical reviews, including those on the anatomy of organic structures. In spite of the discrepancies existing between Vesalius' texts and illustrations on the one hand, and human anatomy on the other, we believe that this reproach is not justified. Although they do indicate transference from observations made in animal anatomy, attention has to be drawn to Vesalius' explicit statement, according to which Galen never dissected a human uterus (a claim implying that he, Vesalius, himself must have done so). $\dagger$ Vesalius substantiated his statement by demonstrating ad oculos the uterus of a dog

* p. 102, footnote (o*): '(dixit etiam tubas vesalius) . . F Fabrica, p. 659 ex animalibus. . . '

$\uparrow$ According to O'Malley, Vesalius dissected at least nine female corpses prior to the publication of the Fabrica (7). 
(fig. 5) as well as of a cow (fig. 6) (figs. 28, 29)-indeed, a very remarkable fact in a fabrica humani corporis-in view of the description of the ancients, propter veterum descriptiones, as he stated in the legend to fig. 28. Reference is made separately to the vas semen a teste deferens in the legends to both pictures. Moreover, that portion of the seminal vessel which Vesalius compared with a nerve morphologically is to be seen very distinctly in both animals.

\section{Vesalius' Original Contributions to the Anatomy of the Uterine Tubes in Comparison with Fallopius}

These descriptions of the 'semen-conveying vessels' raise two questions: What are Vesalius' contributions to the knowledge of the uterine tubes? And second: What prevented Vesalius from 'discovering' the uterine tubes? - a scientific achievement which is usually ascribed to Gabriele Fallopius.

Vesalius' contribution to the knowledge of the uterine tubes consists of two observations:

I. The course of the uterine tube, or the 'semen-conveying vessel', is described and illustrated almost correctly. The 'seminal vessels' surround the ovary in a winding course which begins at the caudal surface of the ovary-but not at the cranial one, as Vesalius still used to demonstrate on earlier pictures in the Tabulae Anatomicae Sex of 1538 (fig. 7), as did Eustachius as well. Vesalius' fig. 25 of Liber $\mathrm{V}$ of the Fabrica represents, indeed, the first modern picture of the uterine tubes.

2. Another concept, still believed in during the sixteenth century, was the theory that the 'female seminal duct' terminated within the myometrium of the uterus, and, consequently, the 'female semen' was discharged into the uterine substance (instead of into its cavity) - even Harvey submitted to this error. ${ }^{8}$ In his comparative studies on animal and human uteri Vesalius aimed at demonstrating functional relations between the relevant organs of both animals and men; a field naturally including the problem regarding the uterine tube's opening into the uterine cavity as well.

The fact, however, which Vesalius was overlooking-and which has to be credited to Fallopius - is that the oviduct does not constitute a 'ductus' morphologically, i.e. it is not an 'excretory duct' of 'semen' (i.e. the egg) from the 'testis' (i.e. the ovary) into the uterus. Fallopius must have been much surprised about his discovery - and it was a real one, indeed! - to find an organ looking like a tube, i.e. a trumpet,* grown together with the uterus, and opening into the abdominal cavity. He was lucky in getting the proper end at the proper corner! What did he say about it?

The following is an excerpt from the Observationes Anatomicae (Venice ${ }_{15} 6_{1}$ ): $\uparrow$

This seminal duct (meatus seminarius) originates from the cornua uteri; it is thin, very narrow, of white colour and looks like a nerve. After a short distance it begins to broaden and to coil like a tendril (capreolus), winding in folds almost up to the end. There, having become very broad, it shows an extremitas of nature of skin and colour of flesh, the utmost end being very ragged and crushed, like the fringe of worn out clothes. Further, it has a great hole which is held closed by the fimbriae which lap over each other. However, if they spread out and dilate,

* The tube was the ancient trumpet of the Roman soldier.

$\dagger$ Cited after Opera Omnia, Frankfurt am Main, 1584, p. 472. 


\section{Robert Herrlinger and Edith Feiner}

they create a kind of opening which looks like the flaring bell of a brazen tube. Because the course of the seminal duct, from its origin up to its end, resembles the shape of this classical instrument-anyhow, whether the curves are existing or not-I named it tuba uteri. These uterine tubes are alike not only in men, but also in the cadavers of sheeps and cows, and all the other animals which I dissected.

The vas semen a teste in utero deferens has thus become a meatus seminarius which originates from the cornu uteri. An organ independent of others, with an abdominal end of a special structure ('of the nature of skin and the colour of flesh'), it is given a proper name: tuba uteri. This being something completely new, it is but reasonable to derive the proper name of the uterine tube from the eponym of Fallopius.

\section{Why did Vesalius not discover the Uterine Tubes?}

Vesalius set out on the path of independent research, freed from Galenic tradition and based solely on personal observation, but he broke off before having reached the goal. There are a vast number of examples to illustrate this.* Galen's descriptions were based on animal rather than on human anatomy, and it is interesting to note that the first of Vesalius' Tabulae Sex (fig. 7) represents an illustration to a Galenic text: a somewhat fantastically shaped uterus bicornis, connected with two seminal ducts which originate from the seminal- (blood)vessels and correspond exactly to the epididymis and the ductus deferens of the male (which are pictured above for comparison). Testis and testis muliebris are hanging aside like assistant 'receptacula'. The course of the vessels is to be followed

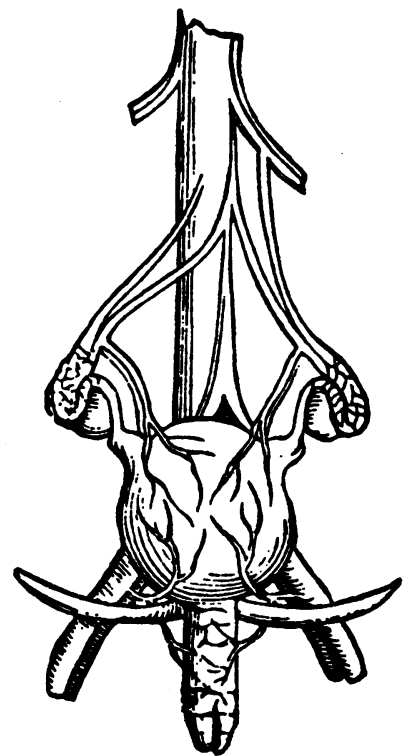

Fig. 7. up like that of a river on a map: the stream of blood is taking its way from the vasa spermatica through the semen-preparing organ (plexus pampiniformis and epididymis of PNA), via the ductus deferens to the uterus. This is the ancient seminal theory in its classical form.

But the Fabrica also contains Galenisms: Galen's concept of analogy which, as we said at the beginning, was inaugurated probably by the school of Alexandria (Herophilus). We should like to make it clear that we do not doubt Vesalius' having taken his morphological descriptions from human anatomy. However, the artist who designed the pictures-even if it had been Vesalius himself $\dagger$-apparently had little opportunity for studying his anatomical material closely enough for the purposes of accurate illustration, and this, no doubt, was the case in the first two books of the Fabrica. It is obvious that Vesalius, guided by the doctrines of Galen and the concept of analogy, corrected a number of drawings and, further, added some of the details he might have

* We have just been referring to another, very impressive example in this connection, i.e. the musculus vesicae cervicem ambiens (9).

$\dagger$ See also O'Malley, Andreas Vesalius of Brussels 1514-1564, p. 127 (7). 


\section{Why did Vesalius not discover the Fallopian Tubes?}

observed during animal dissections. Consequently, the 'female seminal ducts' are coiled around the 'female testis', thus corresponding morphologically to the epididymis of the male. Consequently, too, the female 'ductus deferens' moves in a winding course from the 'testis' to the uterus, in order to make up the lack of distance, which is but the fifth of the course of the male ductus deferens (20:4 inches). Finally, the concept of analogy also serves to explain the place of origin of the female 'seminal duct': the ductus deferens of the male originates from the epididymis and the latter, in turn, from the testis: consequently, the female 'ductus' has to originate from the testis muliebris too. Although Vesalius was no longer blindly copying Galen-at least an advance as compared to the first of his Tabulae Sex of 1538 (fig. 5) -it obviously did not occur to him, during any of his dissections, to examine his female cadavers for the termination of the uterine tube, i.e. to decide whether the final portion of the tube was, indeed, attached firmly to the ovary.

Independence of mind and freedom from Galenic principles took Fallopius one step ahead of Vesalius: Vesalius was not prepared to go on this one step further in the anatomy of the female generative organs, and, therefore, he could not but fail to discover the tuba uterina. Nevertheless, it has to be remembered that Vesalius was the first anatomist to present good descriptions and illustrations of the site of the uterine tubes, in spite of the fact that he believed its abdominal end was attached to the 'testis'.

\section{REFERENCES}

1. Gale n, De Semine, IV, p. 598, ed. Kühn.

2. SORAN, Gynaekologie, I, §12.

3. Ellenberger, W., and Baum, H., Handbuch der vergleichenden Anatomie der Haustiere, 16. Auf., Berlin, Springer, 1926, p. 557.

4. Diepgen, P., Frau und Frauenheilkunde in der Kultur des Mittelalters, Stuttgart, Thieme, 1963, p. 147 .

5. Vesalius, A., De Humani Corporis Fabrica, Basle, 1555, vol. v, p. 659. For further reference see also Eriksson, R., Andreas Vesalius' First Public Anatomy at Bologna, 1540, Uppsala and Stockholm, Almquist and Wiksells, 1959, p. 227.

6. SAUNDeRs, M., and O'MALLey, G. D., The Illustrations from the Works of Andreas Vesalius of Brussels, Cleveland, New York, The World Publ. Co., 1950, p. 172.

7. O'Malley, G. D., Andreas Vesalius of Brussels 1514-1564, Berkeley and Los Angeles, Univ. Calif. Press, 1964, p. 436.

8. Hy rte, J., Onomatologia Anatomica, Wien, r88o, p. 576.

9. Herrlinger, R., Der Sphincter der Harnblase bei Vesal, Scientiarum Historia, 1964. 